\title{
SURGICAL OUTCOME OF SINGLE INCISION LAPAROSCOPIC CHOLECYSTECTOMY IN COMPARISON WITH THE 4-PORT TECHNIQUE IN ZAGAZIG UNIVERSITY HOSPITAL
}

Abd-Elhady Abd-Elaty Salama, Tarek Ezzat Abd-Ellateif ${ }^{M D}$, Tarek Abd Elazeim Gobran* ${ }^{\text {MD }}$, Ahmed Abou Hashem Azab ${ }^{M D}$.

\section{General Surgery \& pediatric Surgery* departments Faculty of Medicine Zagazig University} ABSTRACT

Bachground: Cholelithiasis is one of the most common disorders of the digestive tract encountered by general surgeons worldwide. Conventional or open cholecystectomy was the mainstay of treatment for a long time for this disease. Laparoscopic cholecystectomy (LC) has been the gold standard for removal of the gallbladder since the early 1990s. Single-incision laparoscopic surgery is becoming a more widely accepted surgical approach. However, the feasibility and safety of single-incision laparoscopic cholecystectomy (SILC) are yet to be established. The present study compared outcomes following the use of SILC or conventional laparoscopic cholecystectomy (CLC) on patients with gallbladder disease. Aim: To compare the perioperative results of single port laparoscopic cholecystectomy with the standard 4-port technique. Subjects and methods: The study involved 72 symptomatic gallbladder disease patients underwent laparoscopic cholecystectomy in Zagazig University hospital.36 patients underwent SILC, and 36 patients underwent CLC. Clinical and surgical outcomes were compared. Results: The SILC and CLC groups were similar in terms of age, gender ratio, body mass index, and diagnoses. The two groups were also found to be similar in terms of postoperative clinical course and complications. The SILC group had a longer operation time, less postoperative pain, and a shorter hospital stay with better aesthetic results than the CLC group. Conclusion: SILC was as safe and feasible as CLC. The operating time was longer otherwise it has almost similar clinical outcomes to those of CLC.

Keywords: Four port technique, Laparoscopic surgery, Single port surgery Corresponding author : Abd ElHady Abd ElAty Salama

E mail: drhadysalama@gmail.com

Tel.: 01066797600

\section{INTRODUCTION}

L aparoscopy is now considered the first choice for many abdominal operations ${ }^{(\mathbf{1})}$, and laparoscopic chole-cystectomy (LC) has been the gold standard for removal of the gallbladder since the early 1990 s $^{\text {(2). Open }}$ chole-cystectomy which was first introduced by Langenbuch in 1882 had greatly replaced by Conventional Four Port Laparoscopic Cholecystectomy (C4P LC) done first by Phillipe Mouret in Lyon, Franch in $1987^{(3)}$. The concept has been refined to Single Incision Laparoscopic Cholecystectomy (SILC) with the three-port and two-port (2).

laparoscopic cholecystectomy in between

The (C4PLC) is performed by introducing 4 trocars; one through umbilicas, one through epigastrium and two through the right upper abdominal quadrant ${ }^{(3)}$. In recent years many surgeons have attempted to performe laparoscopic cholecystectomy through single incision at the umbilicus without compromising the safety and benefit of the procedure which has been shown to improve outcomes ${ }^{(4-7) \text {. }}$
The continuous goal of minimal access surgery is to reduce the number and size of the ports. The outcomes in

minimal access surgeries are not only judged by patients' safety but also by a better quality of care in terms of pain, hospital stay and cosmesis. Minimal access or scar-less surgery is an ultimate demand by patients and also strived by surgeons ${ }^{(\mathbf{8})}$

In 1992, Pelosi et al., made the beginning of SILS by performing the first single incision appendicectomy on a child ${ }^{\text {(9). }}$ In 1997, Navarra et al. subsequently performed the first SILS via two trans-umbilical trocars and three transabdominal gall bladder stay sutures (10). We investigate the technical feasibility, safety and surgical outcome of SILC versus C4PLC in our study.

\section{PATIENTS AND METHODS}

A total of 72 patients were included in our study that was performed at Zagazig University hospitals from May 2014 to May 2016. They were divided equally into two groups:

- Group A: Single Incision Laparoscopic Chole-cystectomy (SILC) 
- Group B: Conventional Four-Port

Laparoscopic Cholecystectomy (C4PLC).

This prospective randomized comparative study was aimed at comparing the following parameters in SILC and C4PLC:

- Operative Time (in minutes).

- Surgical related morbidity.

- Mortality.

- Procedure related: CBD injury, GB wall perforation, bleeding from the liver bed, Bile leak, Iatrogenic liver injury.

- Wound haematoma,seroma and infection.

- Port site hernia.

- Conversion to multi-incision/ multiport lap chole or open laparotomy.

- Post-operative Pain.

- Pain score (using VAS).

- Analgesic Requirement (inject-table and tablet).

- Hospital Stay (number of days).

- Cosmetic satisfaction.

\section{Sample selection}

\section{Inclusion Criteria}

Patients between 18 to 60 years of age of either sex with a BMI less than 45 attending the hospital for laparo-scopic cholecystectomy were randomly assigned to either group after taking signed informed consent.

Preoperative work up included a complete history and physical exam-ination, standard laboratory tests including abdominal ultrasound. Ultra-sonography confirmed the presence of gallbladder stones in all patients.

\section{Exclusion Criteria}

- Unwilling Patients.

- Pregnancy.

- Acute cholecystitis.

- Presence of an upper midline or right subcostal incision.

- Preoperative indication for a cholangiogram.

- Presence of an umbilical hernia, or prior umbilical hernia repair.

- Patients suffering from Non-Calcular Cholecystitis.

- Patients with difficulty achieving a regular follow up.

- Any Medical Condition that may render Laparoscopic Surgery hazardus (e.g:Cardiac patients).

\section{STATISTICAL ANALYSIS}

Statistical analysis was done by SPSS version 22.0. Simple comparative statistical analyses were carried out. According to the type of data; qualitative data represented as number and percentage, quantitative continues group represented by mean $\pm \mathrm{SD}$, the following tests were used to test differences for significance; Difference and association of qualitative variable by Chi square test $\left(\mathrm{X}^{2}\right)$. Differences between parametric quantitative independent groups by $\mathrm{t}$ test in paired by paired t. Correlation by Pearson's. P value was set at $<0.05$ for significant results $\&<0.001$ for high significant result.

\section{Surgical Procedure}

Surgeries were performed under general anaesthesia by a single surgeon in supine position. Pneumoperitoneum was created at $12-14 \mathrm{mmHg}$ by Veress needle technique. The conventional four port technique involved inserting a $10 \mathrm{~mm}$ trocar through the umbilical incision through or just above the umbilicus, a second $10 \mathrm{~mm}$ port was inserted in the epigastrium in the midline about $2 \mathrm{~cm}$ below the xiphoid process slightly to the right side of the falciform ligament, one $5 \mathrm{~mm}$ trocar was inserted in the right hypochondrium in the anterior axillary line about $3 \mathrm{~cm}$ below the costal margin and the last $5 \mathrm{~mm}$ trocar was inserted in the right mid clavicular line about $2 \mathrm{~cm}$ from the costal margin. The patient was then placed in reverse Trendelenburg position with a left down tilt.

After clipping the cystic duct and artery the gall bladder is dissected from the liver and extracted through the epigastric or umbilical port.

For the SILC procedure one $1.5-2 \mathrm{~cm}$ incision was made in a vertical fashion through the bottom of the umbilicus without extension of the incision beyond the limit of the umbilical folds. Blunt dissection was used to expose the base of the umbilicus. A fascial incision was made with a scalpel while lifting the umbilicus to accomodate the access port. A haemostat or finger was gently advanced through the fascial incision to ensure that there are no adhesions. The commercial port was then inserted into the peritoneal cavity. Pneumo-peritoneum was created by joining the $\mathrm{CO} 2$ input tube to the inlet in the port and 
the pressure was adjusted to $14 \mathrm{mmHg}$. The patient was then placed in reverse Trendelenburg position with a slight left lateral tilt in order to expose the surgical field. A $10 \mathrm{~mm}$ camera port was used and the routinely available $10 \mathrm{~mm}$ rigid 30 degree telescope introduced to visualize the operative field. We used two $5 \mathrm{~mm}$ ports for the hand instrument and the hook cautery was used during the procedure. The special roticulating graspers and endoscissors and $5 \mathrm{~mm}$ clip applicator were utilized during the procedures. A subcostal suture through the abdominal wall is introduced in the anterior axillary line to retract the fundus, then the gall bladder is dissected in the same way as in the standard 4-port technique and extracted together with the port at the end of the procedure.

\section{RESULTS}

Patient clinical characteristics are summarized in Table 1. There was no difference between the SILC and CLC groups in terms of age, gender ratio, and co morbidities.

Table (1): Patient Characteristics

\begin{tabular}{lccc}
\hline & SILS & Conventional & P. value \\
\hline Age (years) mean \pm SD & $32.08 \pm 7.18$ & $36.22 \pm 10.58$ & 0.056 \\
\hline Sex & & & \\
\hline male & $8.3 \%$ & $25.0 \%$ & 0.057 \\
female & $91.7 \%$ & $75.0 \%$ & \\
Previous Yes & $27.7 \%$ & $38.8 \%$ & 0.31 \\
Operations No & $72.3 \%$ & $61.2 \%$ & \\
\hline Co morbidities & & & \\
\hline Free & 72.3 & 66.7 & \\
DM & 5.5 & 11.1 & \\
Hypertension & 2.77 & 8.3 & \\
cardiac & 2.77 & 5.5 & \\
hepatic & 16.7 & 13.8 & \\
\hline
\end{tabular}

Surgical outcomes and postopera-tive clinical courses are summarized in Tables $2,3 \& 4$. There was no significant difference between the two groups in terms of conversion rate ( $P$ value .39). Due to the complexity of some cases the concept of "Port Rescue" was used in four cases $(12.5 \%)$ in the SILC group, where an additional $5 \mathrm{~mm}$ port was added in two cases to aid with the control of haemorrhage that had resulted from an injury to the cystic artery, and in the other two cases to aid with the dissection of the triangle of Calot. The mean operation time was longer in the SILC group than in the CLC group (P .002).

Postoperative pain was lower in the SILC than the CLC group on the day of surgery and on postoperative Day 7 (P .000) with less need for analgesics in SILC group (P0 .000 for i.v and P 0.003 for oral analgesics). The hospital stay was shorter for the SILC group. 
Table (2): Comparison of Surgical Results

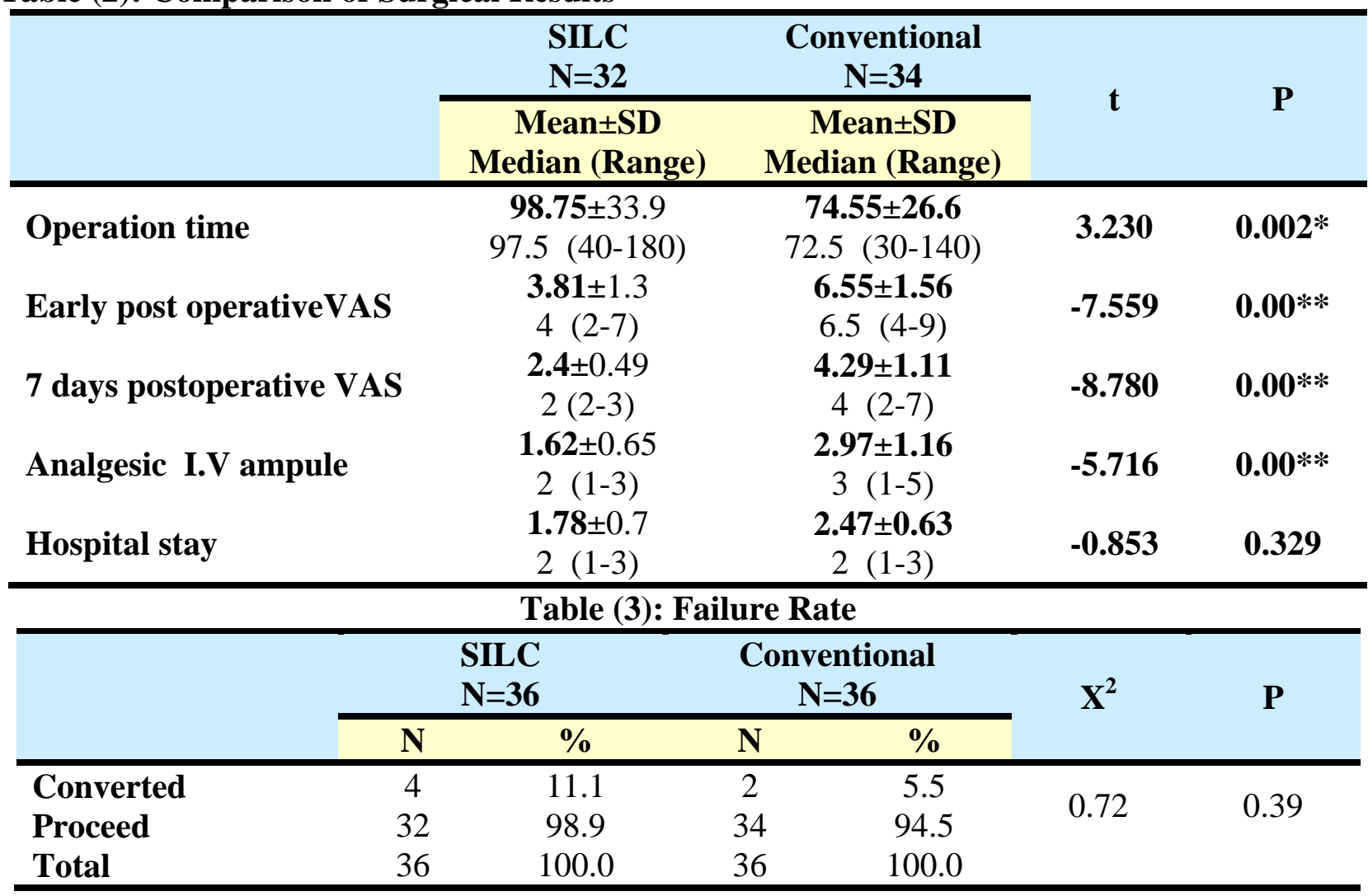

Table (4): Postoperative oral analgesic requirements.

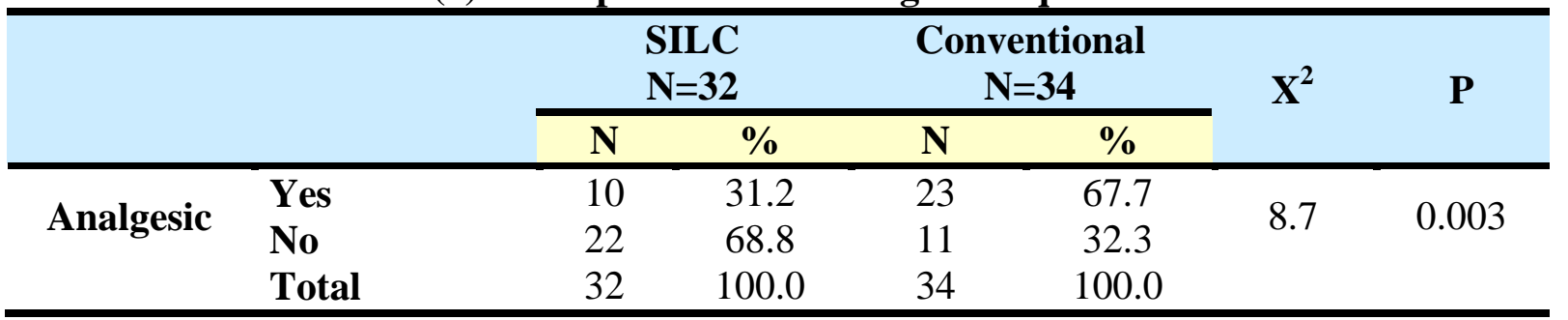

As regards wound infection (table 5), in the MILC group, 11 cases (32.3\%) came presenting with wound infection during the the postoperative follow up. nine of them were at the epigastric port-site. This could be partly attributed to that no "Retrieval Bags" were used that may have caused the contamination of the wound and the occurrence wound infection later on. This could also be attributed to patient's self-hygiene and wound care. On the other hand, only 3 cases in the SILC group $(9.3 \%)$ with wound infections were reported in the SILC group during the postoperative follow up. This could partly be attributed to the fact that most of the single-access devices used has a built in wound protector / retractor as a part of their design. Statistically, that finding was significant $(p$ value $=0.02)$. 
Table (5): wound infection

\begin{tabular}{|c|c|c|c|c|c|c|c|}
\hline & & \multicolumn{2}{|c|}{$\begin{array}{l}\text { SILC } \\
\mathrm{N}=32\end{array}$} & \multicolumn{2}{|c|}{$\begin{array}{c}\text { Conventional } \\
\qquad=34\end{array}$} & \multirow[t]{2}{*}{$\mathbf{X}^{2}$} & \multirow[t]{2}{*}{$\mathbf{P}$} \\
\hline & & $\mathbf{N}$ & $\%$ & $\mathbf{N}$ & $\%$ & & \\
\hline Wound infection & $\begin{array}{l}\text { Yes } \\
\text { No }\end{array}$ & $\begin{array}{c}3 \\
29\end{array}$ & $\begin{array}{c}9.3 \\
90.7\end{array}$ & $\begin{array}{l}11 \\
23\end{array}$ & $\begin{array}{l}32.3 \\
67.7\end{array}$ & 5.2 & $0.02 *$ \\
\hline
\end{tabular}

No port-site hernias were reported in the two groups during the period of postoperative follow up. This probably could be attributed to the close attention payed to the fascial closure done intraoperatively for all patients of both groups.

For reporting and comparing the patients' satisfaction with the aesthetic results of both procedures during the follow ups between the two groups, a visual analog scale with a $5 \mathrm{~cm}$ vertical score ranging from "Not at all satisfied" (score 1) to "Extremely satisfied"' (score 5) was used. Scar satisfaction analyses showed a marked statistically significant differences regarding the aesthetic results between the two groups $(p$ value $=0.000$ ) (table 6). Where most of the cases in the SILC group were very satisfied with the aesthetic results of the single-access approach while, on the other hand, many of the cases in the MILC group were slightly satisfied with the aesthetic results of the conventional approach.

Table (6): Scar Satisfaction parameters Score (1-5)

\begin{tabular}{ccccc} 
& SILC & Conventional & t \\
N=32 & $\mathbf{N}=34$ & P & \\
\hline \multirow{2}{*}{ Satisfaction } & $\mathbf{4 . 3 6} \pm 1.1$ & $\mathbf{2 . 1 8 \pm 0 . 7 1}$ & $\mathbf{7 . 2 1 2}$ & \multirow{2}{*}{$\mathbf{0 . 0 0 * *}$} \\
\hline
\end{tabular}

\section{DISCUSSION}

The progression from open surgery to multi-port laparoscopy to single-port laparoscopy has been an attractive journey. Each step has been marked by introduction of a new technique, evaluation of its safety and results, and eventually acceptance or rejection by the surgical community (11).

The SILS technique is taking surgical practice to the next level, improving what had already been adopted and a step on the road of "Surgery with no scar". Many surgeons claim that it can deliver our patients the benefits of surgery as well as better aesthetic results, less post operative pain, quicker recovery and early return to work ${ }^{(12-14) .}$

Our study aims at exploring that new innovative field, experience its feasibility, and construct an idea regarding its benefits, safety and limitations.

As regards instruments and access devices required to carry out such procedures, in our study, we have tried to put as much SILSdesigned instruments as possible to testing so that we can form a well based opinion whether these devices really help with carrying out such procedures or not, taking in consideration that most of these devices are disposable and this increased the costs of our practice greatly in terms of economic limitations and restrictions.

Surgeons must continue to adhere to the same important surgical principles that guide them during standard four-port laparoscopic cholecystectomy and those should not be skewed for the wrong goals if they compromise safety such as obtaining the "critical view" and initiating dissection high and lateral ${ }^{(15)}$

The addition of an extra $5 \mathrm{~mm}$ or $3 \mathrm{~mm}$ port is not only acceptable but also recommended to maintain safety in aiding the surgeon during dissection or management of intraoperative complications if they arise ${ }^{(16)}$ The concept of "Port Rescue" should never be regarded as a complication or a failure of the surgeon but merely as a means of making the operation easier and safer for a successful outcome $^{(17) \text {. }}$

Concerning the feasibility of SILS technique, operative time and the learning curve; multiple studies have demonstrated difficulties in the acquisition of SILS skills with impaired performances compared to standard laparoscopic surgery. These studies revealed significantly longer learning curves 
for SILS compared to standard multiport laparoscopic surgery ${ }^{(\mathbf{1 8}) \text {. }}$

The mean operative time for our SILC cases was 98.75 minutes while that for our MILC cases was 74.55 minutes.

The mean operative time for the first case series including thirty patients published by Giuseppe Navarra in 1997 was 123 minutes (10).

Ma et al. performed reported longer operative times compared with the standard approach review ${ }^{(\mathbf{1 8}) .}$ Hajong et al. reported a series of 64 patients from 2014 to 2015 divided equally into two groups with an average operative time of 69 minutes for SILC group and 38.5 for conventional group (19).

The rate of occurrence of complications will be the principle factor which will ultimately decide whether a new technique will be accepted and widely used or abandoned ${ }^{\text {(20). }}$

Allemann et al. have performed fifty six Single incision laparoscopic cholecystectomies. They reported only three complications including abscess in the gallbladder fossa, bile leak from the duct of Luschka, and a retained common bile duct stone $^{(15)}$

Regarding the outcomes, Two cases were converted from SILC to MILC due to extensive adhesions that increased the risk of injury, two other cases were converted from SILC to open laparotomy due to the seriousness of the injury inflicted where the duodenumm was injured during its dissection as a result of extensive adhesions and in the other case the common bile duct was injured and the operating surgeon was unable to deal with them laparoscopically.

Due to the complexity of some cases the concept of "Port Rescue" was used in four cases $(12.5 \%)$ in the SILC group, where an additional $5 \mathrm{~mm}$ port was added in two cases to aid with the control of haemorrhage that had resulted from an injury to the cystic artery, and in the other two cases to aid with the dissection of the triangle of Calot.

On the other hand, the failure rate in the MILC group was two cases, where the two cases were converted from MILC to open laparotomy due to injury of the the CBD during dissection and manipulation causing a tear in the CBD that required repair and the surgeon failed to carry out that laparoscopically.

Concerning the postoperative pain, hospital stay and the rate of clinical improvement; Hajong et al. reported that SILC provided less pain, decreased use of analgesics, and faster return to work that help to achieve the concept of one-day surgery ${ }^{(19) .}$

Another report in 2013 by Chang et al. back had also demonstrated lower pain scores in their single-port group ${ }^{(15)}$

In our study, pain score analyses showed significant differences postoperatively regarding port-site pain, both, early and late. Patients in the MILC group usually reported significantly higher pain scores, for almost all of them complained from severe pain at the "epigastric port-site".

As regards the analgesic requirements, there was significant lower I.V. and oral analgesic demands recorded in the SILC group versus the MILC group, both, early postoperatively and during the follow ups and that goes in line with the postoperative portsite pain intensity that the two groups had experienced.

This in turn had translated into shorter hospital stay. The mean postoperative hospital stay for the SILC group in our study was 1.78 days while that for the MILC group was 2.47 days.

Trastulli et al. in their series reported that the mean postoperative hospital stay was 1.8 days which was similar to our results and Song et al. reported that all patients were discharged within the first 24 hours post operatively ${ }^{(21,22)}$

In 2011 Krajinovic et al. reprted that the frequency of incisional hernias after single port laproscopic cholecystectomy amounted to $1.9-2.0 \%$. After adequate closure of the abdominal fascia, the incidence of incisional hernia is not increased after SILS ${ }^{\text {(23). }}$ In 2016 No port site herniation was reported in a study by Hajong et al. ${ }^{(19) .}$

In our study, no port-site hernias were reported in the two groups during the period of the postoperative follow up. This probably could be attributed to the close attention payed to perfect fascial closure done 
intraoperatively for all patients of both groups.

As regards wound infection, in the MILC group, 11 cases $(32.3 \%)$ came presenting with wound infection during the the postoperative follow up. nine of them were at the epigastric port-site. This could be partly attributed to that no "Retrieval Bags" were used during the retrieval of the gall bladder through the epigastric port-site in the MILC series and that may have caused the contamination of the wound and the occurrence wound infection later on. This could also be attributed to patient's self-hygiene and wound care.

On the other hand, only 3 cases in the SILC group (9.3\%) with wound infections were reported in the SILC group during the postoperative follow up. This could partly be attributed to the fact that most of the singleaccess devices used has a built in wound protector / retractor as a part of their design. Statistically, that finding was significant

Finally for the the aesthetic results, many have mentioned that improved cosmesis is the strong foothold of this technique, where the careful reconstruction of the umbilicus leaves no scar in the abdominal wall, yielding a completely invisible scar ${ }^{\text {(24). }}$

Studies by both, Marks et al.and Garg et al. have shown improved cosmesis for patients undergoing SILC, as determined by postoperative surveys of their patients $(\mathbf{1 7 , 2 5 )}$

In our study, great care had been payed to the reconstruction of the umbilicus by the end of the SILC procedure and scar satisfaction analyses later on had showed a significant difference between the two groups. Where most of the cases in the SILC group were very satisfied with the aesthetic results of the single-access approach where it had virtually left no scar at all in the abdominal wall while, on the other hand, many of the cases in the MILC group were slightly satisfied with the aesthetic results of the conventional approach.

\section{CONCLUSION}

SILC is safe and has almost similar clinical outcomes to those of C4PLC, with no obvious increase in bile duct injuries, a reduced need for analgesics, less days of post operative hospital stay, with better aesthetic results in spite of a little more extra operative time. It can be safely offered to patients requiring laparoscopic cholecystectomy.

\section{REFERENCES}

1. Sun S, Yang K, Gao M, He X, Tian J, Ma B. Three port versus four port laparoscopic cholecyste-ctomy: meta-analysis of rando-mized clinical trials. World Surg. 2009; 33(9):1904-08.

2. Soper NJ. Cholecystectomy: from Langenbuch to natural orifice transluminal endoscopic surgery. World J Surg. 2011;35(7):1422-27.

3. Manoj K, Chandra SA, Rakesh KG. Three-port versus standard four-port laparoscopic cholecystectomy: A randomized controlled clinical trial in a community-based teaching hospital in Eastern Nepal. JSLS. 2007;11(3):358-62.

4. Erbella JJ, Bunch GM. Single incision laparoscopic cholecyste-ctomy: the first 100 outpatients. Surg Endosc. 2010;24(8):1958-61.

5. Arezzo A, Scozzari G, Famiglietti F, Passera R, Morino M. Is single-incision laparoscopic cholecystectomy safe? Results of a systematic review and meta-analysis. Surg Endosc. 2013; 27: 2293-304.

6. Geng L, Sun C, Bai J. Single incision versus conventional laparoscopic cholecystectomy outcomes: a meta-analysis of rando-mized controlled trials. PLoS One. 2013;8:e76530.

7. He GL, Jiang ZS, Cheng Y, Lai QB, Zhou CJ, Liu HY, et al. Tripartite comparison of singleincision and conventional laparo-scopy in cholecystectomy: A multicenter trial. World J Gastrointest Endosc. 2015;7:540-46.

8. Waqar SH, Zahid MA. Two- port laparoscopic cholecystectomy: An early experience. J Surg Pakistan. 2009; 14:179-81.

9. Pelosi MA, Pelosi IIIMA. Laparoscopic appendectomy using a single umbilical puncture (minila-paroscopy). J Reprod Med. 1992; 37:58894.

10. Navarra G, Pozze E, Occhio-norelli S, Carcoforo P, Donini I. One-wound laparoscopic cholecys-tectomy. Br J Surg. 1997;84:695.

11. Bucher P, Pugin F, Buchs NC, et al. Randomized clinical trial of laparoendoscopic single-site versus conventional laparoscopic chole-cystectomy. Br J Surg. 2011; 98: 1695-702.

12. Beck C, Eakin J, Dettorre R, Renton D. Analysis of periopera-tive factors and cost comparison of single-incision and traditional multi-incision laparoscopic chole-cystectomy. Surg Endosc. 2013; 27(1): 104-08.

13. Joseph S, Moore BT, Sorensen GB, Earley JW, Tang F, Jones $\mathbf{P}$, et al. Single-incision laparoscopic cholecystectomy: a comparison with the gold standard. Surg Endosc. 2011;25(9):300815. 
14. Chang SK, Tay CW, Bicol RA, Lee YY, Madhavan K. A case-control study of singleincision versus standard laparoscopic cholecystectomy. World J Surg. 2011;35(2):28993.

15. Allemann P, Demartines $N$, Schäfer M. Remains of the day: biliary complications related to singleport laparoscopic cholecys-tectomy. World J Gastroenterol. $2014 ; 20(3): 843-51$.

16. Hauters P, Auvray S, Cardin JL, Papillon M, Delaby $\mathbf{J}$, et al. Comparison between singleincision and conventional laparo-scopic cholecystectomy: a prospe-ctive trial of the Club Coelio. Surg Endosc. 2013;27:1689-94.

17. Garg P, Thakur JD, Garg M, Raina NC, Mittal G, et al. Single- incision laparoscopic cholecystectomy vs. conventional laparo-scopic choolecyste-ctomy: a metaanalysis of randomized controlled trials. J Gastrointes Surg. 2012; 16(8): 1618-28.

18. Ma J, Cassera MA, Spaun GO, et al. Randomized controlled trial comparing single-port laparoscopic cholecystectomy and four-port laparoscopic cholecystectomy. Annals of Surg. 2011; 254(1):22-27.

19. Hajong R, Natung T, Anand M , Sharma G. A Comparative Study of Singl Incision versus Conven-tional Four Ports Laparoscopic Cholecystectomy, Journal of Clini-cal and Diagnostic Research. Oct, Vol-2016; 10(10): PC06-PC09

20. Sajid MS, Ladwa N, Kalra L, Hutson KK, Singh KK, Sayegh M. Single- incision laparoscopic cholecystectomy versus conven-tional laparoscopic cholecyst-ectomy: meta-analysis and systematic review of randomized controlled trials. World $\mathrm{J}$ Surg: 2012; 36: 2644- 2653.

21. Song T, Liao B, Liu J, Yin Y, et al. Singleincision versus conven-tional laparoscopic cholecyst-ectomy: A systematic review of available data. Surg Laparosc Endosc Percutan Tech;2012: 22: e190-e196.

22. Trastulli S, Cirocchi R, Desiderio J, et al. Systematic review and meta-analysis of randomized clini-cal trials comparing singleincision versus conventional laparoscopic cholecystectomy. Br J Surg. 2013; 100 (2):191208.

23. Krajinovic K, Ickrath $P$, Germer $C T$ et al. Trocar-site hernia after singleport cholecystectomy: not an exceptional complication? J Laparoendosc Adv Surg Tech A 2011: 21:919-921

24. Reibetanz J, Ickrath P, Hain J, et al. Single-port laparoscopic cholecystectomy versus standard multiport laparoscopic cholecys-tectomy: A casecontrol study comparing the longterm quality of life and body image. Surg Today;2013: 43: 10251030.

25. Marks JM, Phillips MS, Tacchino R, Roberts K, et al. Single-incision laparoscopic cholecystectomy is associated with improved cosmesis scoring at the cost of significantly higher hernia rates: 1 year result of a prospective randomized, multicenter, single-blinded trial of traditional multiport laparoscopic cholecystectomy vs single-incision laparoscopic chol-ecystectomy. J Am Coll Surg. 2013; 216(6):1037-47. 